\title{
Traditional and Non-Conventional Pasta-Making Processes: Effect on In Vitro Starch Digestibility
}

\author{
Rossella Dodi ${ }^{1}$, Letizia Bresciani ${ }^{1}\left(\mathbb{D}\right.$, Beatrice Biasini ${ }^{1}$, Marta Cossu ${ }^{1}$, Francesca Scazzina ${ }^{1}\left(\mathbb{D}\right.$, Federica Taddei ${ }^{2}(\mathbb{D}$, \\ Maria Grazia D'Egidio ${ }^{2}$, Margherita Dall'Asta ${ }^{3, *}$ and Daniela Martini ${ }^{4}$ (i) \\ 1 Department of Food and Drug, Human Nutrition Unit, University of Parma, 43125 Parma, Italy; \\ rossella.dodi@unipr.it (R.D.); letizia.bresciani@unipr.it (L.B.); beatrice.biasini@unipr.it (B.B.); \\ cossu.marta@gmail.com (M.C.); francesca.scazzina@unipr.it (F.S.) \\ 2 CREA Research Centre for Engineering and Agro-Food Processing, 00189 Rome, Italy; \\ federica.taddei@crea.gov.it (F.T.); mariagrazia.degidio@gmail.com (M.G.D.) \\ 3 Department of Animal Science, Food and Nutrition, Università Cattolica del Sacro Cuore, \\ 29122 Piacenza, Italy \\ 4 Department of Food, Environmental and Nutritional Sciences (DeFENS), Università Degli Studi di Milano, \\ 20133 Milan, Italy; daniela.martini@unimi.it \\ * Correspondence: margherita.dallasta@unicatt.it
}

check for updates

Citation: Dodi, R.; Bresciani, L.; Biasini, B.; Cossu, M.; Scazzina, F.; Taddei, F.; D’Egidio, M.G.; Dall'Asta, M.; Martini, D. Traditional and Non-Conventional Pasta-Making Processes: Effect on In Vitro Starch Digestibility. Foods 2021, 10, 921. https://doi.org/10.3390/ foods10050921

Academic Editors: Joan M. King

Received: 21 March 2021

Accepted: 20 April 2021

Published: 22 April 2021

Publisher's Note: MDPI stays neutral with regard to jurisdictional claims in published maps and institutional affiliations.

Copyright: (c) 2021 by the authors. Licensee MDPI, Basel, Switzerland. This article is an open access article distributed under the terms and conditions of the Creative Commons Attribution (CC BY) license (https:// creativecommons.org/licenses/by/ $4.0 /)$.

\begin{abstract}
Pasta is a carbohydrate-rich food with a low glycemic index (GI) and is one of the main sources of slowly digestible starch (SDS). The presence of bran fractions (BFs) in pasta may enhance its health potential, owing to the content of fiber, micronutrients, and bioactive compounds; however, at the same time, BF may affect starch digestibility. In this study, the bioaccessibility of starch in pasta made with BF-enriched semolina (BF pasta), or only with micronized debranned kernel (DK pasta), and a control pasta made with traditional semolina was evaluated by applying two different in vitro models. The control pasta showed a percentage of SDS about four-fold higher than that of the BF pasta and 1.5-fold higher than that of the DK pasta $(p<0.05)$. The amount of starch released during simulated gastrointestinal digestion was slightly lower, but not significantly different, for the control pasta than for both the BF and DK pasta. These results suggest that the presence of a higher amount of dietary fiber in BF pasta can affect the structure of the food matrix, interfering with the formation of the gluten network, water absorption, and starch granule accessibility, while micronization could enhance starch digestibility due to starch gelatinization. These findings emphasize the need to optimize the process for producing fiber-rich pasta without affecting its low starch digestibility and, consequently, its GI.
\end{abstract}

Keywords: slowly digestible starch; carbohydrates; fiber; in vitro digestion; micronization

\section{Introduction}

Pasta is one of the staple foods of the Mediterranean diet, and it is widely produced and consumed all over the world [1]. In 2019, in Italy-where pasta represents one of the key foods of the gastronomic tradition-consumption reached about $23 \mathrm{~kg} /$ per capita per year [1]. Depending on the total energy intake level, Italian dietary guidelines suggest the daily consumption of 3.5 to 6 portions of carbohydrate-rich foods, such as pasta, rice, and other cereals or cereal-derived products [2], which contribute to the intake of complex carbohydrates both in Italy and in many other countries, even those outside the Mediterranean basin [1,3]. Due to its wide consumption, pasta contributes to covering the recommended $45-60 \%$ of the total daily energy intake from carbohydrates and, if consumed as wholegrain pasta, the suggested dietary target for fiber (at least $25 \mathrm{~g}$ per day) [4].

Besides available starch, pasta-especially when consumed as whole-wheat pasta-is indeed a good carrier of fiber, micronutrients, and bioactive compounds [5,6]. In particular, whole-wheat semolina is rich in fiber, mainly insoluble fiber (e.g., cellulose, arabinoxylans), 
which is well-recognized for its beneficial role in bowel health and many other health outcomes, including a positive role in metabolic health and, thus, in the prevention of several chronic diseases [6-8]. Despite these beneficial effects associated with wholegrain products, the consumption of whole-wheat pasta in Italy still seems limited [9], even though recent data showed a substantial increase in the past decade of launches on the market and the consumption of wholegrain products [10]. Potential barriers to the consumption of wholegrain foods include personal, product-specific, and external factors, such as sensory aspects and dietary habits [11,12]. In particular, inadequate knowledge of the positive effect of wholegrain consumption on chronic disease risk reduction often leads consumers to prefer refined grain products $[13,14]$.

The food structure of pasta is the result of changes occurring in its main components, namely, starch and protein, throughout the technological production process [15], which, in turn, influences the nutritional quality of this product. Indeed, pasta processing leads to an increase in the slowly digestible starch (SDS) fraction in the final product, which elicits a lower post-prandial glycemic response after consumption compared to that from other cereal-based products, such as rice and bread [16]. To date, this is one of the main evidenced reasons behind the beneficial effect of pasta consumption [17-19]. The use of innovative technological processes has been proposed as a strategy to produce cerealbased products such as pasta that preserve the natural health properties of grains while limiting the negative aspects related to the use of wholegrain products [20]. Among these strategies, the use of debranning has been proposed. Debranning consists of pearling and pealing of the kernels that can be used to obtain both selected bran fractions (BFs) and debranned kernels (DKs) [21,22]. Different studies have demonstrated that debranning is a pretreatment potentially able to improve milling yields [23]; moreover, the use of debranning products allows for the making of pasta with a high content of dietary fibers, vitamins, and phenolic compounds and minimal effects on sensory properties, using only the natural endowment of durum wheat $[21,24,25]$. Additionally, preprocessing could reduce the total microbial contamination and the content of mycotoxins or heavy metals in flour, which, in turn, affect its safety and quality [23,26-28].

However, the modification of process parameters may also affect the pasta structure and potentially change the digestibility of the starch and protein fractions $[29,30]$. For instance, the addition of BF or the use of a different process in pasta-making can affect starch digestibility. In fact, the presence of bran within the wholemeal pasta matrix may physically interfere with the gluten matrix, making the structure highly porous, which, in turn, increases the accessibility of the starch granules to $\alpha$-amylase during digestion [15]. Therefore, investigating the starch digestibility in vitro is of physiologic relevance and represents a useful approach for predicting the in vivo bioavailability of carbohydrates contained in pasta and the glycemic index (GI) [31,32].

Thus, because the modification of process parameters may influence the digestibility of starch, influencing both the accessibility to the digestive enzymes and, consequently, the glycemic response in vivo, the aim of the present study was to investigate the in vitro digestibility of starch in pasta produced by using BFs or DKs and to compare it with that of a traditional pasta made with semolina.

\section{Materials and Methods}

\subsection{Chemicals}

Reagents and enzymes were purchased from Sigma-Aldrich (St. Louis, MO, USA), unless otherwise noted. The enzymes used are reported as follows: pepsin (EC number 3.4.23.1), pancreatin (EC number 232-468-9), guar (EC number 232-536-8), invertase (EC number 3.2.1.26), amyloglucosidase (AMG) from E-AMGDF Megazyme kit (Wicklow, Ireland). 


\subsection{Debranning and Traditional Milling Processes}

The Italian Triticum durum wheat Normanno, a widely used Italian durum wheat cultivar, was used as raw materials for the whole experiment. In detail, an aliquot of kernels was debranned three sequential times for about $90 \mathrm{~s}$ each, using a pilot plant (NAMAD, Rome, Italy), to obtain three bran fractions (BFs 1, BFs 2, BFs 3) and aliquots of the resulting kernels (DKs 1, DKs 2, DKs 3), corresponding to ranges of debranning levels (DLs) of $0-2.80 \%, 2.81-5.10 \%$, and $5.11-8.00 \%$, respectively. An additional aliquot of the non-debranned kernels of the same cultivar was traditionally milled in a pilot plant (Buhler MLU 202, Uzwil, Switzerland) to obtain semolina.

\subsection{Pasta Samples: Preparation and Cooking}

Some of the debranning products described in Section 2.1 (i.e., BF2 and DK1) and semolina were used to produce two different pasta samples: (i) BF pasta, produced by enriching semolina with BFs 2 (BFs 2: semolina ratio of 30:100 w/w); and (ii) DK pasta, produced by using only micronized DKs 1 that still include BF2 used for the BF pasta. DK 1 was micronized using a KMX-500 micronizer (Separmicrosystem S.a.S, Brescia, Italy). The third pasta type (control pasta, CTRL), used as a reference, was made by using only semolina obtained as described in Section 2.2. The three samples were processed into spaghetti by an experimental press (NAMAD, Rome, Italy) and were dried using an experimental drier (AFREM, Lyon, France) for $20 \mathrm{~h}$, applying a low-temperature drying process $\left(50^{\circ} \mathrm{C}\right)$. The pasta-making process was repeated twice. A cooking test was performed by adding $100 \mathrm{~g}$ of dried pasta to $1 \mathrm{~L}$ of boiling tap water with a standard cooking time of $13 \mathrm{~min}$. Exhaustive information on the technological process and nutritional composition of the pasta samples was reported in a previous study [24].

\subsection{Available Starch Determination}

Determination of the available starch (Av starch) was carried out using the AOAC Method 2002.02, AACC Method 32-40.01 (Megazyme assay kit, K-RSTAR). The available starch analysis was performed according to the manufacturer's instruction, with slight modifications.

Briefly, $150 \mathrm{mg}$ of cooked and minced pasta was weighed and incubated in a Dubnoff bath (ISCO, Milan, Italy) with pancreatic $\alpha$-amylase and AMG for $16 \mathrm{~h}$ at $37^{\circ} \mathrm{C}$ and 180 strokes/min. After the incubation, $4 \mathrm{~mL}$ of $100 \%$ ethanol was added to each sample and centrifuged at $3000 \mathrm{rpm}$ for $10 \mathrm{~min}$. After the centrifugation, the supernatant was transferred into a $100 \mathrm{~mL}$ matrass. The tubes containing the pellet were washed three times with $50 \%$ aqueous ethanol, dissolved in $2 \mathrm{~mL}$ of $\mathrm{KOH}(2 \mathrm{M})$, and put on ice. After $20 \mathrm{~min}, 8 \mathrm{~mL}$ of sodium acetate buffer (1.2 M, pH 3.8) was added into the samples, and after the addition of $100 \mu \mathrm{L}$ of AMG $(3300 \mathrm{U} / \mathrm{mL})$, the samples were incubated at $50{ }^{\circ} \mathrm{C}$ for $30 \mathrm{~min}$. The samples were centrifuged for $10 \mathrm{~min}$ at $3000 \mathrm{rpm}$ and stored at $-20^{\circ} \mathrm{C}$ until the resistant starch analysis.

A volume of $100 \mathrm{~mL}$ of sodium acetate buffer $(100 \mathrm{mM}, \mathrm{pH} 4.5)$ was added into the matrass containing the supernatant to adjust the total volume. Quantities of $200 \mu \mathrm{L}$ of the solution were transferred into tubes, and $20 \mu \mathrm{L}$ of AMG $(300 \mathrm{U} / \mathrm{mL})$ was added. The tubes were incubated for $20 \mathrm{~min}$ at $50{ }^{\circ} \mathrm{C}$, and the available starch was quantified in the supernatant of the samples by means of an automatic glucose analyzer (model 2900, Yellow Springs Instrument Company, Yellow Springs, OH, USA). The analyses were performed in triplicate for each sample.

\subsection{In Vitro Starch Digestibility}

In vitro digestion of the pasta was performed following the method of Brighenti and colleagues [32], with some modifications [33]. Samples were cooked and extruded through $7 \mathrm{~mm}$ holes of a hand-operated mincer (Sirius, Karl Krüger). Briefly, $8 \mathrm{~g}$ samples were weighed and suspended in $5 \mathrm{~mL}$ of preheated $\left(37^{\circ} \mathrm{C}\right) 20 \mathrm{mM}$ sodium phosphate buffer (pH 6.9, $10 \mathrm{mM} \mathrm{NaCl}$ ) and $25 \mathrm{~mL}$ of preheated $\left(37^{\circ} \mathrm{C}\right) 0.9 \% \mathrm{NaCl}$ with $1.5 \mathrm{~mL}$ of 
human saliva. Saliva was collected from three non-smoking adult donors after careful tooth brushing and abstinence from food and drink for at least $1 \mathrm{~h}$ prior to the experiment. After 2 min incubation in a shaking water bath (SW23, Julabo, Milan, Italy) at $37^{\circ} \mathrm{C}$ and 160 strokes / $\mathrm{min}$, the $\mathrm{pH}$ was adjusted to $2-2.5$ using $5 \mathrm{M} \mathrm{HCl}$. One milliliter of a solution of $0.9 \% \mathrm{NaCl}$ dissolved porcine pepsin $(2500 \mathrm{U} / \mathrm{mL}$ pepsin, was then added to each sample in order to mimic the gastric phase. The mixtures were incubated in a shaking water bath at $37^{\circ} \mathrm{C}$ and 200 strokes/min for $2 \mathrm{~h}$. Intestinal digestion was simulated by correcting the $\mathrm{pH}$ of the samples with $5 \mathrm{M} \mathrm{NaOH}$ to 6.9 and adjusting the volume to $50 \mathrm{~mL}$ with the addition of $20 \mathrm{mM}$ sodium phosphate buffer $(\mathrm{pH} 6.9,10 \mathrm{mM} \mathrm{NaCl})$. After the addition of $100 \mathrm{mg}$ of pancreatin from a porcine pancreas, each sample was transferred into a dialysis tube (12-14 kD, Spectra/Por) with 5 glass marbles. The tubes were sealed and suspended in sealed containers with $600 \mathrm{~mL}$ of $20 \mathrm{mM}$ sodium phosphate buffer $(\mathrm{pH} 6.9,10 \mathrm{mM} \mathrm{NaCl})$.

The containers were incubated for $5 \mathrm{~h}$ in a shaking water bath at $37^{\circ} \mathrm{C}$ and 200 strokes $/ \mathrm{min}$ to simulate the intestinal phase. The dialysate $(1 \mathrm{~mL})$ was collected after $15,30,45,60,90$, $120,150,180,240$, and $300 \mathrm{~min}$ from the start of incubation. Complete starch hydrolysis was carried out by adding $30 \mu \mathrm{L}$ of $0.5 \mathrm{~N}$ acetic acid and $20 \mu \mathrm{L}$ of a solution of AMG from Aspergillus niger (300 U/mL AMG in water) to $0.5 \mathrm{~mL}$ of dialysate and incubating the samples at $60{ }^{\circ} \mathrm{C}$ for $2 \mathrm{~h}$. At the end of the intestinal phase, the glucose concentration derived from starch hydrolysis was quantified using an automatic glucose analyzer (model 2900, Yellow Springs Instrument Company, Yellow Springs, OH, USA). The rate of digested starch from the samples (expressed as the percentage of digested starch) was calculated for each time point as follows: \% digested starch $=($ glucose concentration $\times 0.9 /$ Av starch $) \times$ 100. In vitro digestions were performed in triplicate for each product.

\subsection{Slowly Digestible Starch and Rapidly Digestible Starch Determination}

The percentages of slowly and rapidly digestible starch (SDS and RDS, respectively) were analyzed according to the method proposed by Englyst and colleagues [31], with slight modifications. Briefly, samples were cooked and extruded through $7 \mathrm{~mm}$ holes of a hand-operated mincer (Sirius, Karl Krüger), and then $2 \mathrm{~g}$ of product underwent several enzymatic attacks. After adding $10 \mathrm{~mL}$ of pepsin-guar solution $(5 \mathrm{~g} / \mathrm{L}$ pepsin and $5 \mathrm{~g} / \mathrm{L}$ guar in $0.05 \mathrm{M} \mathrm{HCl}$ ), the samples were vortex-mixed and incubated in a shaking water bath (SW23, Julabo) at $37^{\circ} \mathrm{C}$ and 180 strokes/min for $30 \mathrm{~min}$. Ten milliliters of preheated $\left(37^{\circ} \mathrm{C}\right) 0.25 \mathrm{M}$ sodium acetate were added to 5 glass marbles, and the tubes were mixed and placed in a water bath for $3 \mathrm{~min}$ to equilibrate the temperature. The enzyme mixture was prepared by dissolving $3.3 \mathrm{~g}$ of pancreatin in $22 \mathrm{~mL}$ of distilled water, and the tubes were centrifuged (3200 rpm for $10 \mathrm{~min})$. The supernatant $(15 \mathrm{~mL})$ was collected; then, $3.6 \mathrm{~mL}$ of AMG and $37.5 \mathrm{mg}$ of invertase from baker's yeast (Saccharomyces cerevisiae) were diluted in $3.06 \mathrm{~mL}$ of distilled water and added to the supernatant. Five milliliters of the enzyme mixture were added to each sample, and the samples were incubated in a water bath at $37^{\circ} \mathrm{C}$ and 200 strokes $/ \mathrm{min}$. After $20 \mathrm{~min}$ and $120 \mathrm{~min}, 1 \mathrm{~mL}$ of hydrolysate was centrifuged (14,000 rpm for $5 \mathrm{~min}$ ), and the supernatant was diluted in distilled water (diluted 1:10), then used to determine the total glucose concentration $\left(G_{20}\right.$ and $G_{120}$, respectively).

To determine the free sugar glucose (FSG), the method of Englyst and colleagues [31] was used with some modifications. Briefly, $2 \mathrm{~g}$ of each product was extruded through $8 \mathrm{~mm}$ holes of a hand-operated mincer (Sirius, Karl Krüger) and weighed into plastic flasks. After the addition of $25 \mathrm{~mL}$ of $0.1 \mathrm{M}$ sodium acetate buffer ( $\mathrm{pH} 5.2$ ) and 5 glass marbles, samples were vortex-mixed and incubated in a water bath (SW23, Julabo) at $100{ }^{\circ} \mathrm{C}$ for $30 \mathrm{~min}$. Samples were vortex-mixed again and cooled to $37^{\circ} \mathrm{C}$; then, $0.153 \mathrm{~mL}$ of invertase solution ( $12.3 \mathrm{mg} / \mathrm{mL}$ invertase from baker's yeast (S. cerevisiae) in water) was added to the samples before incubation at $37^{\circ} \mathrm{C}$ and 200 strokes $/ \mathrm{min}$ for $30 \mathrm{~min}$. One milliliter of hydrolysate was collected and centrifuged (14,000 rpm for $5 \mathrm{~min})$, and the supernatant was used to determine the FSG.

The levels of rapidly available glucose (RAG), slowly available glucose (SAG), RDS, SDS, and Av starch were calculated as described by Englyst and colleagues [34]. 
The glucose amounts released after 20 and 120 min and after FSG analysis were quantified by means of an automatic glucose analyzer (model 2900, Yellow Springs Instrument Company, Yellow Springs, OH, USA). The analyses were performed in quadruplicate for each sample.

\subsection{Statistical Analysis}

All the results are expressed as the mean \pm standard deviation (SD). The data distribution was assessed by means of the Shapiro-Wilk test, and the differences among results were studied by analysis of variance through one-way ANOVA and Bonferroni post hoc testing. Statistical significance was determined at $p<0.05$, and the analyses were performed using SPSS Statistics software (version 26, IBM, Armonk, NY, USA).

\section{Results}

\subsection{Starch Digestibility of Pasta Samples}

The percentages of digested starch during the $5 \mathrm{~h}$ intestinal phase digestion are shown in Figure 1, with a focus on the percentages of starch digested after 120 and $300 \mathrm{~min}$ (Figure 1). After $120 \mathrm{~min}$ of simulated digestion, the BF pasta presented the highest percentage of starch digestion (39.67 $\pm 1.54 \%$ ), followed by the DK (38.77 $\pm 3.63 \%$ ), while the CTRL pasta showed the lowest percentage $(38.66 \pm 2.32 \%)$. After $300 \mathrm{~min}$ of digestion, the different starch digestibility percentages were $81.24 \pm 1.62 \%, 82.44 \pm 2.09 \%$, and $78.42 \pm 2.02 \%$ for BF, DK, and CTRL, respectively. Although a trend of reduced starch release during the digestion of CTRL compared to the two pasta samples produced via a non-conventional process was observed, no statistically significant differences among the samples were evident $(p>0.05)$.

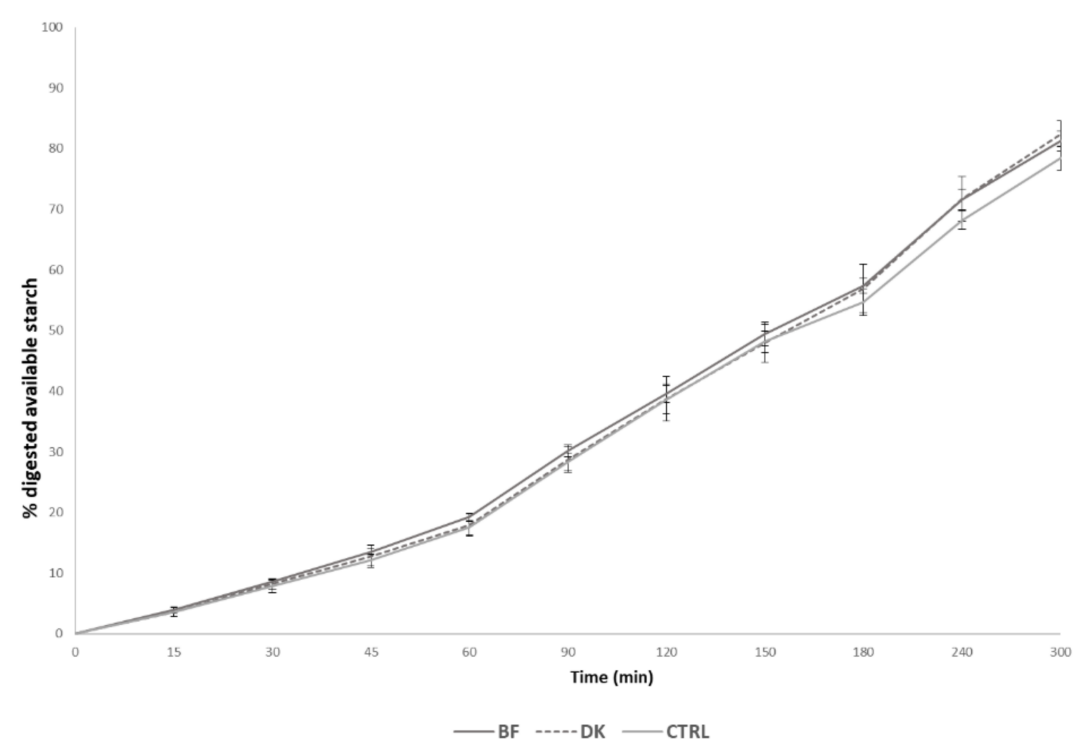

Figure 1. Lines represent the digested starch reported as a percentage of the total available starch during the in vitro digestion of each test food. Values are reported as the mean \pm standard deviation (SD) $(n=3)$. BF: pasta produced by enriching semolina with a durum wheat bran fraction; CTRL: control, pasta produced by traditional milling; DK: pasta produced by using micronized debranned kernels. Statistical analysis was performed via one-way ANOVA and Bonferroni post hoc testing $(p<0.05)$.

\subsection{Slowly and Rapidly Digestible Starch Determination}

The values of RAG, SAG, RDS, SDS, Av starch, and FSG are reported in Table 1. BF had the highest amounts of RAG $(17.81 \pm 0.91 \mathrm{~g} / 100 \mathrm{~g})$ and RDS $(15.71 \pm 0.99 \mathrm{~g} / 100 \mathrm{~g}) \mathrm{com}-$ pared to the DK and CTRL samples. On the contrary, the CTRL pasta showed the highest 
values for SAG, SDS, and Av starch $(8.94 \pm 1.23,8.04 \pm 1.11$, and $20.16 \pm 0.98 \mathrm{~g} / 100 \mathrm{~g}$, respectively).

Table 1. The RAG, SAG, SDS, RDS, Av starch, and FSG values of the pasta samples assessed by an in vitro method. Values are expressed as the mean $\pm \mathrm{SD}(n=4)$.

\begin{tabular}{ccccccc}
\hline Pasta Products & RAG (g/100 g) SAG (g/100 g) & SDS (g/100 g) & RDS (g/100 g) & $\begin{array}{c}\text { Av Starch } \\
(\mathbf{g} / \mathbf{1 0 0} \text { g) }\end{array}$ & FSG (g/100 g) \\
\hline BF & $17.81 \pm 0.91^{\mathrm{a}}$ & $1.95 \pm 0.72^{\mathrm{c}}$ & $1.75 \pm 0.65^{\mathrm{b}}$ & $15.71 \pm 0.99^{\mathrm{a}}$ & $17.46 \pm 0.37^{\mathrm{b}}$ & $0.36 \pm 0.01^{\mathrm{b}}$ \\
\hline DK & $14.88 \pm 0.32^{\mathrm{b}}$ & $4.78 \pm 0.39^{\mathrm{b}}$ & $4.30 \pm 0.35^{\mathrm{b}}$ & $12.91 \pm 0.28^{\mathrm{b}}$ & $17.21 \pm 0.21^{\mathrm{b}}$ & $0.54 \pm 0.01^{\mathrm{a}}$ \\
\hline CTRL & $13.77 \pm 0.27^{\mathrm{b}}$ & $8.94 \pm 1.23^{\mathrm{a}}$ & $8.04 \pm 1.11^{\mathrm{a}}$ & $12.11 \pm 0.24^{\mathrm{b}}$ & $20.16 \pm 0.98^{\mathrm{a}}$ & $0.31 \pm 0.00^{\mathrm{b}}$ \\
\hline
\end{tabular}

Av starch: available starch; BF: pasta produced by enriching semolina with a durum wheat bran fraction; CTRL: control, pasta produced by traditional milling; DK: pasta produced by using micronized debranned kernels; FSG: free sugar glucose; RAG: rapidly available glucose; RDS: rapidly digestible starch; SAG: slowly available glucose; SDS: slowly digestible starch. Data in the same column with different letters indicate significant differences at $p<0.05$, according to Bonferroni post hoc testing.

The percentage contributions of RDS and SDS to the Av starch (considered as 100\%) are graphically reported in Figure 2. The ratio between SDS and Av starch was different among the three samples; in fact, the control (CTRL) showed a percentage four-fold higher than that for the BF and 1.5-fold higher than that for the DK sample.

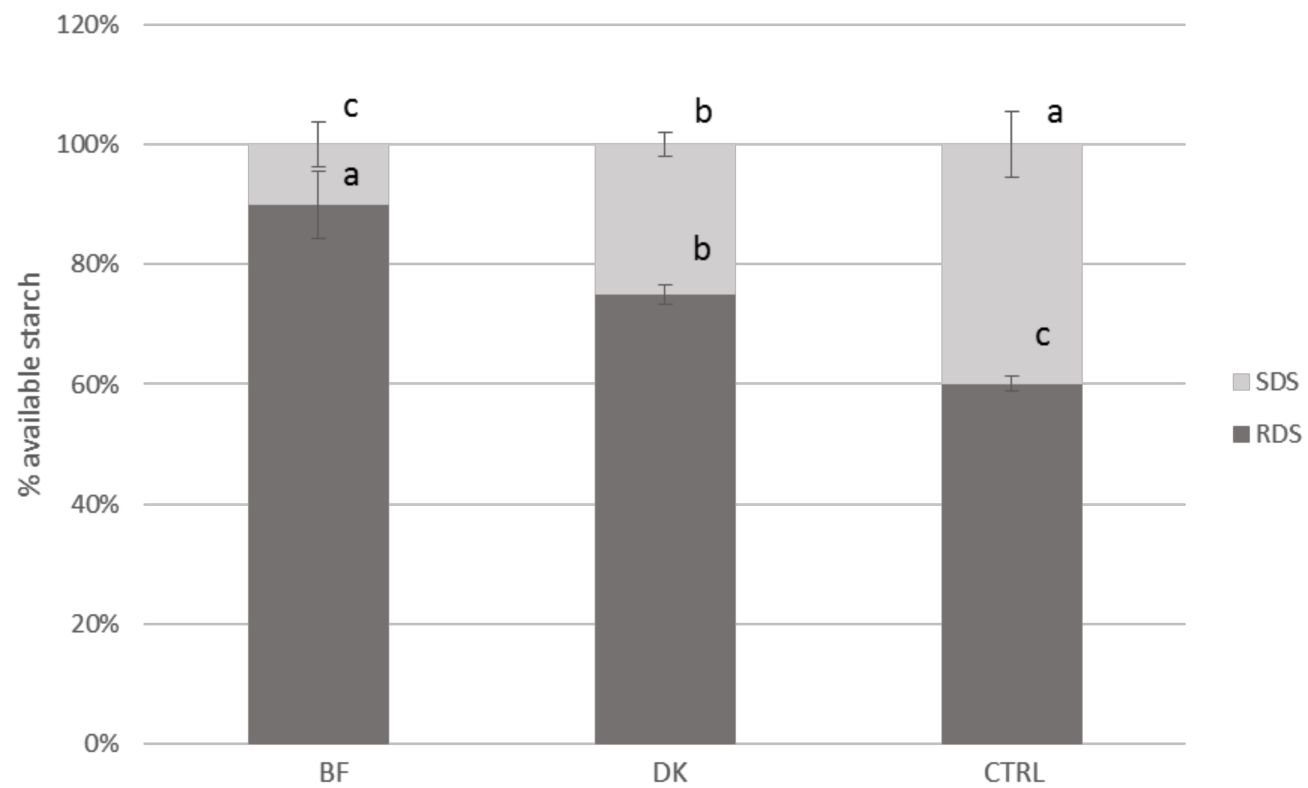

Figure 2. RDS and SDS expressed as percentages of the available starch (mean \pm SD) $(n=4)$ for the pasta samples. BF: pasta produced by enriching semolina with a durum wheat bran fraction; CTRL: control, pasta produced by traditional milling; DK: pasta produced by using micronized debranned kernels; RDS: rapidly digestible starch; SDS: slowly digestible starch. Statistical analysis was performed via one-way ANOVA and Bonferroni post hoc testing. Different letters indicate statistical significance $(p<0.05)$.

\section{Discussion}

The present study aimed at evaluating the in vitro digestibility of three different pasta samples made from the cultivar Normanno using different types of pasta-making processes. In particular, this study explored the impact of the use of debranned products on the starch digestibility of pasta by applying two different methods for investigating the digestibility of starch, both recognized as suitable for assessing starch digestibility in food products [35]. The results of the present work reveal that the CTRL pasta showed the highest value of SDS/Av starch and the lowest value of RDS/Av starch, which could 
reflect a lower glycemic response in vivo compared to the BF and DK samples [36]. The process applied for enriching the pasta with fiber and bioactives seems ineffective in maintaining a compact starch matrix. This could be ascribable to the different process applied for the production of pasta samples. This may lead to the presence of a high amount of dietary fiber in BF pasta that could affect the structure of the food matrix, interfering with the formation of the gluten network, water absorption, and starch granule accessibility [37]. The DK pasta showed intermediate values of SDS/Av starch and RDS/Av starch, which could be due to the smaller size of bran particles. Moreover, it was previously shown that micronized samples of barley and maize pasta exhibited increased starch digestibility, and this could be attributed to starch gelatinization during micronization without significant retrogradation during storage $[38,39]$. When the method proposed by Brighenti and colleagues was applied, the same trend of starch digestibility was observed, with the CTRL showing a slightly lower starch release during digestion, even though no statistically significant differences were observed. However, the differences obtained between the two in vitro methods could be ascribable to the difference in the oral phase and in the incubation system [40]. Starch bioaccessibility is indeed influenced by, among other things, the mastication process. Through mastication, food is broken into smaller pieces, and the rate of digestion also depends on the time and the intensity of chewing, mainly due to the contact of the food surface with saliva $\alpha$-amylase, responsible for the first starch hydrolysis [41]. However, the structural properties of pasta products can lead to different breakdown patterns during mastication and, consequently, different in vitro digestibility [42].

The debranning process improves the yield and degree of semolina refinement and enhances the nutritional value of the end-products [21], allowing us to obtain BFs with high fiber and bioactive contents. This process was used in combination with micronization, a technological process which enables a reduction in the food matrix into a fine powder, improving the bioaccessibility of the bioactive compounds [43] and making the bran particles smaller, lowering the impact of the dietary fiber on the gluten matrix. However, several studies have demonstrated the impact of fiber on the rate of starch digestion, with non-starch polysaccharides being responsible for discontinuity in the network, leading to faster hydrolysis. The addition of fiber to durum wheat pasta can interfere with the gluten structure, thus disrupting the continuity of the protein-starch matrix and making the starch granules more susceptible to enzymatic degradation [37]. In addition to fiber, starch digestibility in cereal-based products can be affected by several other factors, including the type and source of starch, the presence of protein matrixes, and the processing method [44].

In a previous study [24], pasta produced with debranning products (DK and BF) presented higher contents of phenolic compounds and other bioactives compared to traditional pasta, with minimal effects on its sensory properties [25]. However, the effect on starch digestibility related to the presence of debranning products has not been investigated. Bioactives present in foods may also play a key role in reducing the post-prandial glycemic response of carbohydrate-rich foods in vivo [45]. This can be mediated by the direct inhibition of starch enzymatic digestion, but also by other physiological mechanisms, such as inhibition of the absorption and potentially increased insulin release at the $\beta$-pancreatic level [45]. Therefore, we can hypothesize that a higher amount of bioactives in BF and DK samples may lead to a reduced glycemic response in vivo, which is strictly dependent on the bioaccessibility of phenolic compounds.

Diets exerting a low glycemic response favorably affect glucose metabolism and health status [46] and have been associated with a lower risk of many chronic diseases, such as type 2 diabetes and other cardiometabolic diseases, compared to high-GI diets [18,46,47]. In this scenario, pasta is a milestone in several healthy eating patterns, such as the Mediterranean diet, and its consumption is associated with several health benefits [17-19,48]. The consumption of pasta has decreased in recent years, probably because its consumption is wrongly associated with the myth of weight gain from the consumption of carbohydraterich foods [49]. However, recent studies have investigated the effect of pasta consumption 
on body weight and disease risk. Several publications have emphasized the beneficial role of pasta consumption on the obesity epidemic and cardiometabolic risk factors both in healthy subjects and in obese and diabetic patients [20-22,37]. In particular, pasta consumption, in the context of a low-GI diet, has shown to be involved in the reduction in body weight and markers of adiposity, such as waist circumference and waist-to-hip ratio [19]. Similar results emerged from another clinical trial recently conducted on obese patients [17]. In this study, the consumption of a hypocaloric diet characterized by an intake of at least five portions per week of pasta led to a higher reduction in body weight compared to the consumption of a lower amount of pasta ( $\leq 3$ portions/week). Finally, patients with type 2 diabetes did not show worse glucose control, measures of adiposity, or major cardiovascular risk factors when pasta was included in their diet within the recommended consumption amount [48]. Based on this evidence, the present work focused on the importance of producing high-quality pasta, taking into account several nutritional factors.

Finally, it is worth noting that "pasta" as a category includes a large number of heterogeneous types of products which differ in shape, ingredients, and nutritional composition, eliciting different responses in humans [50]. Considering the crucial role of pasta in several dietary patterns and the overall high worldwide consumption, it is worth investigating strategies for maximizing the nutritional quality of this product, preserving its naturally high SDS content. Therefore, the investigation of starch digestion in non-conventional pastamaking processes seems to be a potential strategy to obtain pasta with high contents of SDS, fiber, micronutrients, and bioactives to increase its health-related beneficial properties.

\section{Conclusions}

The starch digestibility of the BF and DK pasta samples after in vitro simulated gastrointestinal digestion was affected by the non-conventional pasta-making process applied to the samples, as compared to the traditional process. Enriching pasta with bran fractions seems to affect starch digestibility by decreasing the SDS content, while this effect was less obvious in pasta made with micronized debranned kernels. However, the traditional pasta-making process led to the product with the highest amount of SDS. This result may depend on the different structural properties of the three pasta samples, leading to differences in the rate of starch digestion in vitro. Therefore, further investigations should focus on the evaluation of the microstructure of pasta samples, and in vivo studies are needed to clarify the role of debranning products and the micronization process on the GI of pasta products. Moreover, future studies should also investigate the bioaccessibility and bioavailability of polyphenolic compounds from BF and DK pasta samples, to obtain a clearer picture of the overall nutritional quality of these products. Considering that dietary guidelines suggest the consumption of low-GI and high-fiber foods, it is strongly advisable to further explore new technologies for preserving the low impact of pasta on post-prandial glycaemia but guaranteeing the presence of fiber, the global consumption of which is still lower than the recommendations.

Author Contributions: Conceptualization, D.M. and M.D.; methodology, M.D. and D.M.; formal analysis, L.B., M.C., and F.T.; investigation, B.B. and M.C.; resources, F.S. and M.G.D.; data curation, R.D. and L.B.; writing—original draft preparation, R.D., M.D., D.M.; writing-review and editing, B.B., L.B., F.S., F.T., and M.G.D.; supervision, D.M. All authors have read and agreed to the published version of the manuscript.

Funding: This research was funded by the AGER Project, grant no. 2010-0262.

Institutional Review Board Statement: Not applicable.

Informed Consent Statement: Not applicable.

Conflicts of Interest: The authors declare no conflict of interest. 


\section{References}

1. International Pasta Organisation (IPO). The World Pasta Industry Status Report; International Pasta Organization: Rome, Italy, 2019; Available online: http:/ / www.internationalpasta.org (accessed on 1 March 2021).

2. Consiglio per la ricerca in agricoltura e l'analisi dell'economia agraria (CREA). Guidelines for Healthy Italian Nutrition. 2019. Available online: https:/ / www.crea.gov.it/web/alimenti-e-nutrizione/- /linee-guida-per-una-sana-alimentazione-2018 (accessed on 1 March 2021).

3. Leclercq, C.; Arcella, D.; Piccinelli, R.; Sette, S.; Le Donne, C. The Italian national food consumption survey INRAN-SCAI 2005-06: Main results in terms of food consumption. Public Health Nutr. 2009, 12, 2504-2532. [CrossRef] [PubMed]

4. Società Italiana di Nutrizione Umana. Larn—Livelli di assunzione di Riferimento di Nutrienti ed Energia per la Popolazione Italiana, 4th ed.; Società Italiana di Comunicazione Scientifica e Sanitaria (SICS): Milano, Italy, 2014.

5. Saura-Calixto, F.; Goñi, I. Definition of the Mediterranean diet based on bioactive compounds. Crit. Rev. Food Sci. Nutr. 2009, 49, 145-152. [CrossRef] [PubMed]

6. Augustin, L.S.A.; Aas, A.M.; Astrup, A.; Atkinson, F.S.; Baer-Sinnott, S.; Barclay, A.W.; Brand-Miller, J.C.; Brighenti, F.; Bullo, M.; Buyken, A.E.; et al. Dietary fibre consensus from the International Carbohydrate Quality Consortium (ICQC). Nutrients 2020, 12, 2553. [CrossRef] [PubMed]

7. Ciudad-Mulero, M.; Fernández-Ruiz, V.; Matallana-González, M.C.; Morales, P. Dietary fiber sources and human benefits: The case study of cereal and pseudocereals. Adv. Food Nutr. Res. 2019, 90, 83-134.

8. Del Bo, C.; Bernardi, S.; Marino, M.; Porrini, M.; Tucci, M.; Guglielmetti, S.; Cherubini, A.; Carrieri, B.; Kirkup, B.; Kroon, P.; et al. Systematic review on polyphenol intake and health outcomes: Is there sufficient evidence to define a health-promoting polyphenolrich dietary pattern? Nutrients 2019, 11, 1355.

9. Sette, S.; D'Addezio, L.; Piccinelli, R.; Hopkins, S.; Le Donne, C.; Ferrari, M.; Mistura, L.; Turrini, A. Intakes of whole grain in an Italian sample of children, adolescents and adults. Eur. J. Nutr. 2017, 56, 521-533. [CrossRef]

10. Whole Grain Statistics. Available online: https://wholegrainscouncil.org/newsroom/whole-grain-statistics (accessed on 1 March 2021).

11. Neo, J.E.; Brownlee, I.A. Wholegrain food acceptance in young Singaporean adults. Nutrients 2017, 9, 371. [CrossRef]

12. Van der Kamp, J.W.; Poutanen, K.; Seal, C.J.; Richardson, D.P. The healthgrain definition of 'whole grain'. Food Nutr. Res. 2014, 58. [CrossRef]

13. Foster, S.; Beck, E.; Hughes, J.; Grafenauer, S. Whole grains and consumer understanding: Investigating consumers' identification, knowledge and attitudes to whole grains. Nutrients 2020, 12, 2170. [CrossRef]

14. Barrett, E.M.; Foster, S.I.; Beck, E.J. Whole grain and high-fibre grain foods: How do knowledge, perceptions and attitudes affect food choice? Appetite 2020, 149, 104630. [CrossRef]

15. Petitot, M.; Abecassis, J.; Micard, V. Structuring of pasta components during processing: Impact on starch and protein digestibility and allergenicity. Trends Food Sci. Tech. 2009, 20, 521-532. [CrossRef]

16. Scazzina, F.; Dall'Asta, M.; Casiraghi, M.C.; Sieri, S.; Del Rio, D.; Pellegrini, N.; Brighenti, F. Glycemic index and glycemic load of commercial Italian foods. Nutr. Metab. Cardiovasc. Dis. 2016, 26, 419-429. [CrossRef] [PubMed]

17. Rosi, A.; Tesan, M.; Cremonini, A.; Biasini, B.; Bicchieri, L.; Cossu, M.; Brighenti, F.; Dall'Aglio, E.; Scazzina, F. Body weight of individuals with obesity decreases after a 6-month high pasta or low pasta Mediterranean diet weight-loss intervention. Nutr. Metab. Cardiovasc. Dis. 2020, 30, 984-995. [CrossRef] [PubMed]

18. Huang, M.; Li, J.; Ha, M.A.; Riccardi, G.; Liu, S. A systematic review on the relations between pasta consumption and cardiometabolic risk factors. Nutr. Metab. Cardiovasc. Dis. 2017, 27, 939-948. [CrossRef] [PubMed]

19. Chiavaroli, L.; Kendall, C.W.C.; Braunstein, C.R.; Blanco Mejia, S.; Leiter, L.A.; Jenkins, D.J.A.; Sievenpiper, J.L. Effect of pasta in the context of low-glycaemic index dietary patterns on body weight and markers of adiposity: A systematic review and meta-analysis of randomised controlled trials in adults. BMJ Open 2018, 8, e019438. [CrossRef] [PubMed]

20. Patel, S. Cereal bran fortified-functional foods for obesity and diabetes management: Triumphs, hurdles and possibilities. J. Funct. Foods 2015, 14, 255-269. [CrossRef]

21. Dexter, J.E.; Wood, P.J. Recent applications of debranning of wheat before milling. Trends Food Sci. Tech. 1996, 7, 35-41. [CrossRef]

22. Martini, D.; D'Egidio, M.G.; Nicoletti, I.; Corradini, D.; Taddei, F. Effects of durum wheat debranning on total antioxidant capacity and on content and profile of phenolic acids. J. Funct. Foods 2015, 17, 83-92. [CrossRef]

23. Mousia, Z.; Edherly, S.; Pandiella, S.S.; Webb, C. Effect of wheat pearling on flour quality. Food Res. Int. 2004, 37, 449-459. [CrossRef]

24. Ciccoritti, R.; Taddei, F.; Nicoletti, I.; Gazza, L.; Corradini, D.; D’Egidio, M.G.; Martini, D. Use of bran fractions and debranned kernels for the development of pasta with high nutritional and healthy potential. Food Chem. 2017, 225, 77-86. [CrossRef]

25. Martini, D.; Ciccoritti, R.; Nicoletti, I.; Nocente, F.; Corradini, D.; D’Egidio, M.G.; Taddei, F. From seed to cooked pasta: Influence of traditional and non-conventional transformation processes on total antioxidant capacity and phenolic acid content. Int. J. Food Sci. Nutr. 2018, 69, 24-32. [CrossRef]

26. Laca, A.; Mousia, Z.; Díaz, M.; Webb, C.; Pandiella, S.S. Distribution of microbial contamination within cereal grains. Food Eng. 2006, 72, 332-338. [CrossRef]

27. Tibola, C.S.; Guarienti, E.M.; Dias, A.R.G.; Nicolau, M.; Devos, R.J.B.; Teixeira, D.D. Effect of debranning process on deoxynivalenol content in whole-wheat flours. Cereal Chem. 2019, 96, 717-724. [CrossRef] 
28. Giordano, D.; Blandino, M. Arsenic, lead and cadmium distribution in the pearled fractions of different winter wheat cultivars (Triticum aestivum L.). J. Cereal Sci. 2018, 80, 94-101. [CrossRef]

29. Foster-Powell, K.; Holt, S.H.A.; Brand-Miller, J.C. International table of glycemic index and glycemic load values: 2002. Am. J. Clin. Nutr. 2002, 76, 5-56. [CrossRef] [PubMed]

30. Atkinson, F.S.; Foster-Powell, K.; Brand-Miller, J.C. International tables of glycemic index and glycemic load values: 2008. Diabetes Care 2008, 31, 2281-2283. [CrossRef] [PubMed]

31. Englyst, K.N.; Englyst, H.N.; Hudson, G.J.; Cole, T.J.; Cummings, J.H. Rapidly available glucose in foods: An in vitro measurement that reflects the glycemic response. Am. J. Clin. Nutr. 1999, 69, 448-454. [CrossRef] [PubMed]

32. Brighenti, F.; Pellegrini, N.; Casiraghi, M.C.; Testolin, G. In vitro studies to predict physiological effects of dietary fibre. Eur. J. Clin. Nutr. 1995, 49, S81-S88.

33. Zaupa, M.; Scazzina, F.; Dall'Asta, M.; Calani, L.; Del Rio, D.; Bianchi, M.A.; Melegari, C.; De Albertis, P.; Tribuzio, G.; Pellegrini, N.; et al. In vitro bioaccessibility of phenolics and vitamins from durum wheat aleurone fractions. J. Agric. Food Chem. 2014, 62, 1543-1549. [CrossRef]

34. Englyst, K.N.; Hudson, G.J.; Englyst, H.N. Starch analysis in food. In Encyclopedia of Analytical Chemistry; Meyers, R.A., Ed.; John Wiley \& Sons Ltd.: Chichester, UK, 2000; pp. 4246-4262.

35. EFSA Panel on Dietetic Products, Nutrition and Allergies (NDA). Scientific Opinion on the substantiation of a health claim related to "slowly digestible starch in starch-containing foods" and "reduction of post-prandial glycaemic responses" pursuant to Article 13(5) of Regulation (EC) No 1924/2006. EFSA J. 2011, 9, 2292.

36. Englyst, H.N.; Veenstra, J.; Hudson, G.J. Measurement of rapidly available glucose (RAG) in plant foods: A potential in vitro predictor of the glycaemic response. Br. J. Nutr. 1996, 75, 327-337. [CrossRef]

37. Gallo, V.; Romano, A.; Masi, P. Does the presence of fibres affect the microstructure and in vitro starch digestibility of commercial Italian pasta? Food Struct. 2020, 24, 100139. [CrossRef]

38. Emami, S.; Meda, V.; Pickard, M.D.; Tyler, R.T. Impact of micronization on rapidly digestible, slowly digestible, and resistant starch concentrations in normal, high-amylose, and waxy barley. J. Agric. Food Chem. 2010, 58, 9793-9799. [CrossRef] [PubMed]

39. Deepa, C.; Sarabhai, S.; Prabhasankar, P.; Hebbar, H.U. Effect of micronization of maize on quality characteristics of pasta. Cereal Chem. 2017, 94, 840-846. [CrossRef]

40. Germaine, K.A.; Samman, S.; Fryirs, C.G.; Griffiths, P.J.; Johnson, S.K.; Quail, K.J. Comparison of in vitro starch digestibility methods for predicting the glycaemic index of grain foods. J. Sci. Food Agric. 2008, 88, 652-658. [CrossRef]

41. Blanquet-Diot, S.; François, O.; Denis, S.; Hennequin, M.; Peyron, M.A. Importance of oral phase in in vitro starch digestibility related to wholegrain versus refined pastas and mastication impairment. Food Hydrocoll. 2021, 112, 106277. [CrossRef]

42. Alam, S.A.; Pentikäinen, S.; Närväinen, J.; Katina, K.; Poutanen, K.; Sozer, N. The effect of structure and texture on the breakdown pattern during mastication and impacts on in vitro starch digestibility of high fibre rye extrudates. Food Funct. 2019, 10, 1958-1973. [CrossRef] [PubMed]

43. Hemery, Y.M.; Anson, N.M.; Havenaar, R.; Haenen, G.R.M.M.; Noort, M.W.J.; Rouau, X. Dry-fractionation of wheat bran increases the bioaccessibility of phenolic acids in breads made from processed bran fractions. Food Res. Int. 2010, 43, 1429-1438. [CrossRef]

44. Singh, J.; Dartois, A.; Kaur, L. Starch digestibility in food matrix: A review. Trends Food Sci. Technol. 2010, 21, 168-180. [CrossRef]

45. Dall'Asta, M.; Del Rio, D.; Tappy, L.; Potì, F.; Agostoni, C.; Brighenti, F. Critical and emerging topics in dietary carbohydrates and health. Int. J. Food Sci. Nutr. 2020, 71, 286-295. [CrossRef]

46. Augustin, L.S.; Kendall, C.W.; Jenkins, D.J.; Willett, W.C.; Astrup, A.; Barclay, A.W.; Bjorck, I.; Brand-Miller, J.C.; Brighenti, F.; Buyken, A.E.; et al. Glycemic index, glycemic load and glycemic response: An international scientific consensus summit from the International Carbohydrate Quality Consortium (ICQC). Nutr. Metab. Cardiovasc. Dis. 2015, 25, 795-815. [CrossRef]

47. Giacco, R.; Costabile, G.; Della Pepa, G.; Anniballi, G.; Griffo, E.; Mangione, A.; Cipriano, P.; Viscovo, D.; Clemente, G.; Landberg, R.; et al. A whole-grain cereal-based diet lowers postprandial plasma insulin and triglyceride levels in individuals with metabolic syndrome. Nutr. Metab. Cardiovasc. Dis. 2014, 24, 837-844. [CrossRef]

48. Vitale, M.; Masulli, M.; Rivellese, A.A.; Bonora, E.; Babini, A.C.; Sartore, G.; Corsi, L.; Buzzetti, R.; Citro, G.; Baldassarre, M.P.A.; et al. Pasta consumption and connected dietary habits: Associations with glucose control, adiposity measures, and cardiovascular risk factors in people with type 2 diabetes-TOSCA IT study. Nutrients 2019, 12, 101. [CrossRef] [PubMed]

49. Montel Press Office. Italy's Love of Pasta Goes off the Boil: Sales of Pasta Fall by 2\%. Available online: https://www.mintel.com/ press-centre/food-and-drink/italys-love-of-pasta-goes-off-the-boil (accessed on 1 March 2021).

50. Dello Russo, M.; Spagnuolo, C.; Moccia, S.; Angelino, D.; Pellegrini, N.; Martini, D.; On Behalf of the Italian Society of Human Nutrition Sinu Young Working Group. Nutritional quality of pasta sold on the Italian market: The food labelling of Italian products (flip) study. Nutrients 2021, 13, 171. [CrossRef] [PubMed] 